\title{
ENSINO-APRENDIZAGEM EM GEOGRAFIA: CONTRIBUIÇÕES DA INICIAÇÃO CIENTÍFICA
}

Paulo Marcelo de Souza Reis

DOI: $10.15628 /$ geoconexoes.2018.6639

\section{RESUMO}

O artigo apresenta análise do papel assumido pelas atividades desenvolvidas em Projeto de Iniciação Científica, financiado pelo Instituto Federal do Pará (IFPA), para o ensino-aprendizagem com ênfase para os debates geográficos. Os procedimentos metodológicos foram compostos pela revisão de referencial teórico, o acompanhamento sistemático da execução do Projeto, e aplicação de questionário com a bolsista. 0 conjunto de ações indicou a realização das orientações contidas nos manuais de pesquisa e a participação discente, ativa em todas as fases da pesquisa. Concluise, portanto que as atividades propostas no âmbito dos Projetos de Iniciação Científica, auxiliaram a inserção discente na pesquisa e na apropriação dos temas elementares da Geografia, contribuindo para estimular o processo de ensino-aprendizagem e a construção do conhecimento geográfico.

PALAVRAS-CHAVE: Ensino-aprendizagem. Iniciação Científica. Campus Marabá Industrial-IFPA.

\section{ABSTRACT:}

The paper presents an analysis of the role assumed by the activities developed in the Scientific Initiation Project, funded by the Federal Institute of Pará (IFPA), for teaching-learning with emphasis on geographical debates. The methodological procedures were composed by the revision of theoretical reference, systematic monitoring of the project execution, and questionnaire application with the scholarship holder. The set of actions indicated the accomplishment of the guidelines contained in the research manuals and the student participation, active in all phases of the research. It is concluded, therefore, that the activities proposed in the scope of the Scientific Initiation Projects, helped the student insertion in the research and appropriation of the elementary themes of Geography, contributing to stimulate the teaching-learning process and the construction of geographic knowledge.

KEYWORDS: Teaching-learning. Scientific research. Campus Marabá Industrial-IFPA.

\section{INTRODUÇÃO}

O processo de ensino-aprendizagem com ênfase para as análises das perspectivas e limitações da prática docente envolve um conjunto diversificado de demandas orientadas para a participação ativa dos discentes, como subsídio para a ampliação do alcance dos resultados e consolidação dos objetos de estudos em diferentes ramos do conhecimento. Nesse universo, ganha relevo o desenvolvimento dos Projetos de Iniciação Científica, como um grupo de ações que permite a integração de práticas diversificadas, ampliando as possibilidades para a obtenção de resultados positivos. 
Partindo do reconhecimento das múltiplas oportunidades apresentadas pela pesquisa científica, mas também as demandas que integram a participação de discentes do Ensino Médio em atividades práticas, constitui objetivo apresentar análise do papel assumido pelas atividades desenvolvidas em Projeto de Pesquisa intitulado "Avaliação de Impactos Socioambientais Urbanos no Rio Tocantins em Marabá (PA)", financiado pelo Programa Institucional de Bolsas de Iniciação à Pesquisa Científica, Tecnológica e de Inovação (PIBCTI), do Instituto Federal do Pará (IFPA), no campus Marabá Industrial, e sua influência para o processo de ensino-aprendizagem com ênfase para a compreensão das temáticas geográficas.

Ademais, sobressaiu-se a busca pelo reconhecimento do significado assumido pelo referido Projeto, para a prática das atividades discentes, buscando a construção de inter-relações entre pesquisa e a edificação das diretrizes do ensino-aprendizagem, no âmbito do curso técnico Integrado em Controle Ambiental do IFPA.

A justificativa para a construção da investigação foi fundamentada na necessidade de identificação dos limites e possibilidades oferecidos pela pesquisa científica em um universo composto por demandas que englobam as disciplinas da base comum e àquelas inerentes ao ensino técnico. Dessa forma, depreende-se que o Ensino Médio Integrado apresenta a necessidade de atividades diversificadas no campo da prática docente, especialmente pelas demandas atribuídas aos discentes, que ao concluírem o Ensino Médio, deverão apresentar qualificação orientada para atuação no mercado de trabalho.

A ênfase para as análises geográficas está relacionada às características dos debates propostos para o Projeto de Pesquisa, composto pela adoção da análise socioespacial para a promoção de investigação e efetivação da Avaliação de Impactos Socioambientais. Para tanto, os procedimentos metodológicos foram compostos pela revisão de referencial teórico, abordando temas como a iniciação científica, pesquisa, ensino-aprendizagem em Geografia, além do acompanhamento sistemático das etapas efetuadas ao longo da execução do Projeto, e aplicação de questionário junto a discente que atuou no Projeto, objetivando a construção de fundamentos para a compreensão da relevância assumida pela iniciação científica, para o processo de ensino-aprendizagem.

Visando a apresentação dos resultados, o artigo está estruturado em seções que possibilitam inicialmente a apresentação do debate teórico acerca das características da prática docente, e as interelações com as atividades que constituem subsídios para a promoção de processo de ensinoaprendizagem que envolva ativamente a participação discente. Posteriormente tem-se a exposição das características da Instituição e das demandas que integram o ensino Técnico Integrado, sendo acompanhada pelas discussões sobre as atividades que foram desenvolvidas ao longo da prática do Projeto de Pesquisa.

\section{INICIAÇÃO CIENTÍFICA E ABORDAGENS GEOGRÁFICAS: PERSPECTIVAS PARA O ENSINO-APRENDIZAGEM}

No contexto do processo de ensino-aprendizagem em Geografia, ganha ênfase o papel exercido pelas orientações voltadas para a compreensão da dinâmica do seu objeto de estudo. Nessa 
perspectiva, observa-se que ela possui como campo de estudo, o espaço geográfico correspondendo àquele produzido pelas sociedades humanas ao longo do tempo, envolvendo entre outros, a dinâmica socioambiental. Assim, a análise do espaço geográfico demonstra que ele está sujeito a um processo mediado por constantes alterações, que concorrem para os processos de produção resultantes dos desdobramentos das ações dos agentes.

Dessa forma, quando pensada a atividade docente em consonância com as peculiaridades demandadas pela abordagem dos objetos de estudo, defende-se que ela apresenta possibilidades de análises mediadas pela relevância do papel do profissional, mas também pelas requisições impostas diariamente e pelo conjunto de demandas que devem ser trabalhadas, com vistas ao desenvolvimento satisfatório das tarefas e os respectivos resultados.

No conjunto de orientações discutidas, quando se analisa o trabalho em sala de aula, destacamse as observações de Perrenoud (2000) ao defender a necessidade de estimular a constituição de processos voltados para o estímulo do desejo de aprender e do saber nos alunos. Logo, é necessário considerar que essas ações estão relacionadas à busca pela constituição de uma razão para a realização.

Além disso, conforme Perrenoud (1999) torna-se fundamental a elaboração de planejamentos compostos pela flexibilidade, constituídos a partir das ações que antecederam a prática no momento atual. Essas características permitiriam a interrupção da linearidade na medida em que possibilitaria o surgimento de atividades novas que não seriam ignoradas e cujos trabalhos enriqueceriam as atividades. Busca-se ainda através das situações problema, promover alterações no papel dos alunos, mediante o estabelecimento de um novo contrato didático, onde o discente pode expor suas dúvidas, participar da elaboração de projetos e competências, valorizando a prática da cooperação entre agentes.

Perrenoud (1999) ressalta ainda que essas possibilidades devem estar associadas a uma avaliação formativa e certificativa, adotando propriedades como análises coletivas, abandono da avaliação como recurso punitivo para a pressão, optando pela criação de situações amplas que permitam o envolvimento dos alunos na avaliação, buscando fugir da avaliação padronizada que não permitem análises envolvendo as novas características propostas para uma prática docente encaminhada para a construção de saberes com a comunidade escolar.

Essas colocações auxiliam a fundamentação das experiências desenvolvidas para o ensino de Geografia, pois apresentam exigências que se impõem a prática docente como iniciativas que possibilitam despertar a atenção dos discentes, envolvendo-os nas atividades não apenas como sujeitos passivos, mas também como agentes ativos que contribuem para a construção do processo de ensino - aprendizagem auxiliando o desenvolvimento de aprendizagens significativas para a vida cotidiana.

Tardif e Lessard (2012) abordam três questões que nos últimos vinte anos estiveram no centro da problemática de profissionalização do ensino e da formação dos professores num grande número de países ocidentais. Dentre elas, a epistemologia da prática profissional definida como estudo do conjunto de saberes utilizados realmente pelos profissionais em seu espaço de trabalho cotidiano para desempenhar todas as sua tarefas. Sob este aspecto, defende a associação, na formação universitária das conjunturas internacional, regional e local a realidade de sala de aula. Ainda segundo esse autor, 
os saberes são situados, isto é, elaborados e utilizados em função demandas apresentadas por uma situação de trabalho particular.

Sendo assim, o professor elabora seus saberes no contexto da realização de suas atividades. Logo a compreensão da prática docente como aspecto para debates sobre a construção de conhecimentos revela que as atividades no âmbito da sala não podem estar restritas ao trabalho com conteúdos teóricos.

Para tanto, algumas exigências são impostas aos professores, como aquelas relacionadas ao trabalho com as representações dos alunos, mediante análise de erros e obstáculos que poderão constituir fundamentos para discussões, estimulando também a efetivação de perguntas. Assim, a docência na visão de Tardif (2005), é um trabalho cujo objeto não é constituído de matéria inerte ou de símbolos, mas de relações humanas com pessoas capazes de iniciativa e dotadas de certa capacidade de resistir ou de participar da ação dos professores.

Do exposto, a docência, como resultado das relações humanas, é construída de erros e acertos em sua prática. Esse grupo de possibilidades, quando reunido, poderá fornecer subsídios para o estímulo à aprendizagem. Além disso, torna-se essencial conhecer as características da comunidade em que os alunos estão inseridos como oportunidade para a elaboração de atividades que envolvam as heterogeneidades, comuns a turmas em contextos diversos (TARDIF, 2005).

A compreensão da prática docente como aspecto para debates sobre a construção de conhecimentos revela que as atividades no âmbito da sala, não podem estar restritas ao trabalho com conteúdos teóricos. Nesse sentido, Lessard e Tardif (2012) ressaltam que a ação cotidiana dos profissionais docentes deve ser considerada como um espaço de produção envolvendo saberes, teorias e o saber fazer. Nessa perspectiva, o saber não estaria relacionado apenas à teoria, mas também à prática, demonstrando, portanto, a necessidade de observação atenta das discussões que consideram a prática docente apenas como uma atividade para aplicações práticas dos conhecimentos debatidos nas universidades.

As observações elencadas por Lessard e Tardif (2012) revelam a preocupação com as análises das teorias que estão sendo elaboradas por pesquisadores que investigam os diversos ramos do conhecimento, mas também os anseios, propostas e possibilidades pensadas, trabalhadas e vivenciadas a partir das particularidades das atividades diárias das salas de aula inseridas no contexto de grupos sociais compostos por alunos com objetivos, comportamentos e histórias diversificadas e escolas com características peculiares que embora adotem bases comuns exigidas pela legislação e seus instrumentos, são dotados de algumas individualidades.

Nesse sentido, observa-se a importância assumida pelo reconhecimento das demandas do ensino-aprendizagem, logo, para Castrogiovani (2011) conhecer não corresponde ao ato de dar as respostas para todas as perguntas. Essa tarefa seria mediada pela atividade de busca e proposição de interrogações, inteirando desafios, incertezas, fragilidades, articulando o conhecimento construído institucionalmente com aqueles saberes produzidos no cotidiano. Dessa forma, as abordagens que englobam o conhecimento geográfico devem considerar a dinamicidade da Geografia.

0 conjunto dessas ações auxilia a participação ativa e constituição de processos que estejam orientados pelos fundamentos básicos para o ensino, e que atuarão na efetivação de propostas que 
possam ultrapassar a simples transmissão de conhecimento, desenvolvendo perspectivas compostas pelo professor que atua como mediador dos processos.

Do exposto, sobressai-se a necessidade de reconhecimento das peculiaridades que integram as diferentes áreas do conhecimento. Logo, quando pensada a Geografia, verifica-se que o processo de ensino-aprendizagem nesta ciência engloba a relevância da análise do cotidiano, atribuindo significado para a efetivação de observações que revelam as características dos contextos que se configuram em dado recorte espacial, assim Kaercher (2003) defende que os trabalhos com a Geografia envolvem o dia a dia, mediado pelas práticas de agentes e processos voltados para determinados objetivos. Dessa forma, as aulas de Geografia deveriam proporcionar inicialmente a análise do espaço vivido dos alunos, contribuindo para uma leitura crítica dos instrumentos que apresentam um fluxo contínuo, aliados a uma diversidade de informações como a imprensa.

Essas observações são reforçadas por Silva, Melo e Silva (2011) ao afirmarem que os conteúdos e aulas de Geografia devem auxiliar no conhecimento dos fenômenos, que acontecem no contexto das possibilidades dos grupos de alunos que se observa, permitindo que estes compreendam 0 seu papel na produção espacial enquanto agentes ativos, constituindo dessa forma, subsídio para o entendimento dos processos efetivados em diferentes escalas, pois os conteúdos não podem ser totalmente abandonados.

Corroborando com as observações, Calvacanti (2008) afirma que os alunos devem ser compreendidos como sujeitos do processo de conhecimento, considerando a diversidade de contextos que integram a vivência dos discentes. Para tanto, estes precisam estar envolvidos diretamente através de propostas que busquem a integração entre atividades, visando ir além da memorização e permitindo a constituição de significações.

Na elaboração de concepções geográficas, diversas demandas são impostas à prática docente que se processa, conforme Cavalcanti (2008) no âmbito das tecnologias de informação e comunicação inseridas em cidades que guardam complexidade e diversidade da experiência humana com ênfase para o predomínio da urbanização marcada pela variedade de grupos, redes sociais e manifestações culturais, características que tornam a vida cotidiana marcada pelo encanto, mas também pelas múltiplas diferenciações.

Sobressai-se ainda a importância da transposição didática que configuraria a geografia escolar em associação ao funcionamento didático e a dinâmica social, considerando as demandas acadêmicas e sociais, a partir da compreensão das particularidades que integram a geografia acadêmica e a escolar (CAVALCANTI, 2008).

Nessa perspectiva, ainda conforme a autora supramencionada, algumas preocupações teóricas para o ensino de geografia ganham destaque, dentre elas, a importância das análises sobre o lugar, a articulação entre o local e o global, a formação de conceitos, inserção de temas emergentes, desenvolvimento da linguagem cartográfica, educação ambiental e abordagem de outras formas de linguagem.

Nesse universo, Cavalcanti (2008) destaca que o desenvolvimento do pensar em Geografia demanda a construção de conceitos pelos alunos, como subsídio para transformar o conhecimento geográfico em instrumento. No levantamento dos conceitos, o debate sobre o lugar guarda a importância 
assumida pela discussão sobre a identidade, englobando a escala local, mas também as influencias exercidas pelo debate global.

Somam-se também as análises sobre o conceito de paisagem que estaria relacionado a descrições associadas aos aspectos técnicos, funcionais e estéticos da sociedade e no âmbito do ensino de Geografia possibilitaria a constituição de entendimento acerca da forma e conteúdo que compõem o espaço geográfico. 0 conceito de território abordaria, por outro lado, a identidade e as inter-relações entre indivíduos e seus lugares, ganhando ênfase também, a caracterização deste como campo de forças. Além disso, o conceito de cidade possibilitaria o conhecimento da espacialidade contemporânea permitindo também o trabalho com os demais conceitos geográficos (CAVALCANTI, 2008).

Esse arcabouço indica um conjunto de demandas para a construção de conhecimentos geográficos, dessa forma, ganha destaque a necessidade de adoção de metodologias diversificadas, capazes de permitir que os alunos possuam uma participação ativa. Nessa perspectiva, Furlan (2006) observa que os trabalhos com projetos têm sido uma maneira de organizar o trabalho pedagógico nas diferentes áreas que integram a formação do estudante, além disso, essa prática permite a análise das estruturas internas dos conteúdos abordados, aliados aos demais processos trabalhados pelo professor ao longo do desenvolvimento dos conteúdos.

$\mathrm{Na}$ oportunidade, a autora ressalta também os aspectos elementares na elaboração de projetos para que estes sejam capazes de proporcionar uma aprendizagem significativa dos conteúdos. Para tanto, faz-se necessário considerar a natureza interna e a função social, a forma como se desenvolve a aprendizagem, o modo como são planejadas as intervenções, envolvendo conceitos espontâneos e científicos, além das múltiplas perspectivas para a efetivação de avaliação do processo de ensinoaprendizagem.

Considerando as demandas apresentadas para a construção do conhecimento em sala de aula, com ênfase para a Geografia, sobressai-se o papel das pesquisas ensejadas no contexto da iniciação científica, pois como observam Moura, Barbosam, Moreira (2008) a escola tem o papel de formar seres críticos e participativos, conscientes de seu papel diante das mudanças sociais, especialmente quando se considera o mundo atual, com tantas transformações e novas demandas, exigindo dos indivíduos a construção de habilidades e atitudes diferenciadas.

Compreendendo a dinâmica socioespacial na atualidade, verifica-se que o cidadão deste século necessita se inserir adequadamente num mundo social e tecnológico cada vez mais complexo. Precisa saber pensar e refletir sobre os conhecimentos disponibilizados através das novas tecnologias de informação e comunicação, além de possuir habilidades para realizar pesquisa e selecionar as informações para, a partir delas e da própria experiência, construir o conhecimento (MOURA, BARBOSAM, MOREIRA, 2008).

Corroborando com as discussões, Furlan (2006) salienta algumas demandas inerentes à prática com projetos, entre elas a compreensão das dificuldades que integram os trabalhos com projetos, a atenção durante o processo de elaboração dos objetivos, fato que exige o planejamento. Além disso, é importante atentar para a demanda de escolha de um tema capaz de abarcar os conceitos e procedimentos elementares para a prática do processo de aprendizagem. Destaca-se ainda o fato de que 
[...] sempre estruturamos o trabalho a partir de conteúdos. 0 emprego de projetos educativos vincula a importância atribuída aos conteúdos. 0 emprego de projetos educativos vincula a importância atribuída aos conteúdos à interpretação transmissiva e cumulativa do ensino-aprendizagem. Isso não quer dizer valorizar menos os conteúdos, mas sim ter critérios de seleção que considerem sua importância social e, ao mesmo tempo, uma abordagem socioconstrutivista, que valoriza os conhecimentos dos alunos, além da necessária mediação do professor (FURLAN, 2006, p.11).

Depreende-se, portanto que o desenvolvimento de projetos deve estar vinculado aos requisitos que integram o saber docente, com ênfase para a possibilidade de envolvimento dos conteúdos curriculares, mediado pela compreensão de ações que consideram os conhecimentos produzidos em contextos que ultrapassam o ambiente escolar. Nesse sentido, mediado pelo professor, seriam proporcionadas possibilidades de ultrapassar o ensino tradicional.

Dessa forma, a dinâmica do ensino-aprendizagem de Geografia, exige a constituição de um arcabouço de práticas capazes de proporcionar a construção de conhecimentos fundamentados na participação efetiva do discente durante as aulas, assim como em outras atividades, como a iniciação científica, que possibilitem o desenvolvimento de habilidades elementares para a produção do conhecimento. Essas observações concorrem para o reconhecimento das peculiaridades assumidas pelo debate em escala local.

\section{CAMPUS MARABÁ INDUSTRIAL-IFPA: INSTALAÇÃO E TRAJETÓRIA}

O Campus Marabá Industrial (CMI) está localizado no município de Marabá, na região Sudeste do Pará, distante 654 km da capital, Belém. 0 município possui área geográfica de 15.128,058 km e uma população de 233.669 habitantes (IBGE, 2010). Nesse contexto, verifica-se que o CMI exerce influência sobre os municípios situados próximos à Marabá. (Figura 1) 


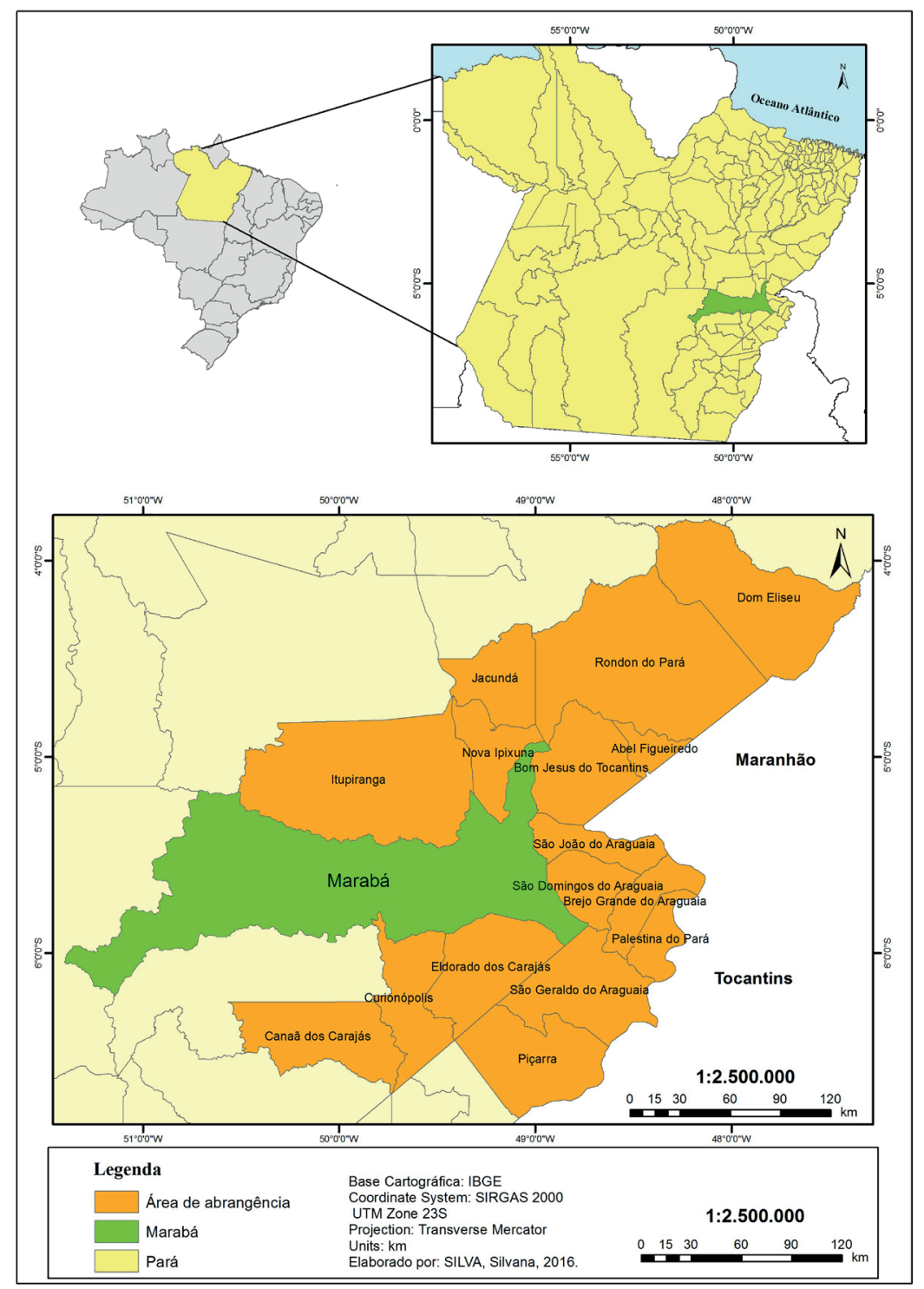

Figura 1- Área de Abrangência do campus Marabá Industrial. Fonte: Elaborado com dados do IBGE, 2016.

$\mathrm{Na}$ caracterização da trajetória do CMI, verifica-se que este iniciou sua atuação no ano de 1995 , quando a Companhia Vale do Rio Doce (CVRD) disponibilizou uma área para construção de estrutura orientada para a implantação do curso Técnico em Edificações. Posteriormente, foi criada a Unidade de Ensino Descentralizada de Marabá - UNED, responsável pela oferta dos cursos de Processamento de Dados, Registro de Saúde e Desenvolvedor e Organizador de Eventos (IFPA, 2017).

Quando a CVRD realizou a doação da área onde se instalara a UNED-Marabá para Prefeitura Municipal de Marabá, e esta repassou a sede para o Ministério da Educação, foram implantados os cursos técnicos subsequentes em Agrimensura, Informática e Edificações (IFPA, 2017).

Em 2009, o IFPA estabeleceu convênio com a CVRD para a implantação dos cursos subsequentes de Química, Mecânica e Eletrotécnica, somados ao curso Técnico em Automação Industrial, objeto do mesmo convênio, entretanto, ofertado posteriormente (IFPA, 2017). A partir do ano de 2016, tem-se início a oferta de Cursos Técnicos Integrados ao Ensino Médio com os cursos de Informática e Controle 
Ambiental, e o de Eletrotécnica, no ano de 2017.

Diante da instalação recente do Ensino Médio Integrado, que constitui uma realidade diferente da vivenciada até então, verifica-se que um conjunto de demandas se impôs a partir da constituição de cenários marcados, por exemplo, pelos índices elevados de retenção e evasão escolar no ano letivo de 2016. Esse quadro constituiu um conjunto de indicadores que apontaram para a adoção de análises, objetivando o reconhecimento dos fatores que concorreram para a configuração dos resultados negativos. Destacando-se também a necessidade da constituição de ações para intervenções e análises das práticas que culminaram na obtenção de resultados exitosos. Entre essas perspectivas, destaca-se o papel exercido pelas atividades de iniciação científicas, que também apresentaram baixa disseminação no referido ano letivas.

\section{INICIAÇÃO CIENTÍFICA NO CAMPUS MARABÁ INDUSTRIAL-IFPA E ENSINO-APRENDIZAGEM}

Os debates sobre a iniciação científica permitem observar o conjunto de possibilidades oferecidas pelas pesquisas, demandando a abordagem em escala local. Dessa forma, considerando as características do $\mathrm{CMI}$, onde são trabalhados os eixos tecnológicos: Controle e Processos Industriais, Informática e Comunicação Infraestrutura e Produção Industrial e Ambiente e Saúde, destacou-se como campo para análises, relativas ao processo de ensino-aprendizagem e Iniciação Científica, o Curso Integrado em Controle Ambiental que objetiva formar o Técnico em Controle Ambiental Integrado ao Ensino Médio que atue com eficiência no reconhecimento, avaliação e gerenciamento das questões ambientais, e tenha a competência de conhecer e utilizar tecnologias de controle da poluição ambiental (MARABÁ INDUSTRIAL, 2016).

Nesse contexto, destacou-se para a análise, o Projeto de Iniciação Científico intitulado "Avaliação de Impactos Socioambientais Urbanos no rio Tocantins em Marabá (PA)". O Projeto adotou como questões problemas: quais os impactos ambientais urbanos coexistentes na bacia hidrográfica do Rio Tocantins, em Marabá (PA)? Quais as possíveis implicações desses impactos para as atividades desenvolvidas pelos agentes produtores que desenvolvem relações diretas com o Rio Tocantins?

Do exposto, o Projeto considerou as demandas analíticas sob a ótica da Geografia e inseridas no âmbito do espaço urbano, no qual se verifica a coexistência de dinâmicas diversificadas, envolvendo os agentes produtores e as inter-relações com os componentes ambientais, constituindo dessa forma, cenários que exigem a configuração de abordagens das características dos processos espaciais. Em uma caracterização dos impactos socioambientais, constata-se que a análise deste exige uma adequada qualificação a partir de um determinado ponto de análise. Além disso, é necessário debater a confusão teórica entre impacto ambiental e dano ambiental, pois o termo dano está vinculado aos conceitos legais de poluição e degradação, que por sua vez estão ligados à definição de qualidade ambiental, a partir do momento em que essas alterações prejudicam o bem estar, a saúde e a segurança da população. Dessa forma, comumente é realizada uma confusão entre o impacto e o prejuízo (FENKER, 2007). 
Nesse contexto, o termo impacto socioambiental remete a essa relação entre sociedade e meio ambiente. 0 conjunto de práticas indica que os agentes sociais interferem excessivamente no meio natural causando consequências negativas, e que muitas vezes afetam a própria população. Dessa forma, "os problemas ambientais que ocorrem nas cidades são, por princípio, problemas socioambientais, pois a cidade é o mais claro exemplo de espaço onde as interações entre a Natureza e a Sociedade se concretizam" (MENDONÇA, 2004, p.204).

A análise da relevância das leituras sobre a cidade, urbana e impactos ambientais em Marabá, são defendidos por Salis e Oliveira (2013), ao indicarem que as margens dos rios Tocantins e Itacaiúnas que cortam a cidade, apresentam-se bastante devastadas e seus leitos alterados em virtude da retirada ilegal de areia e cascalho e outras atividades, além da urbanização de forma acelerada próximo às suas margens. Na margem Tocantina organizou-se uma ocupação tipicamente ribeirinha, no entanto, o crescimento urbano apresenta contradições relacionadas a existência de esgotos sem tratamento, lixos domésticos, e outros materiais lançados diariamente nas margens e no leito dos rios.

Verifica-se, portanto que o objeto de estudo que compõe o Projeto de Pesquisa, está vinculado à realidade urbana em escala local, característica que está associada a demandas pela abordagem da realidade como subsídio para a aplicação dos conteúdos trabalhados em sala durante as aulas de Geografia.

Na caracterização das atividades no âmbito do Projeto de Pesquisa, verifica-se que estas iniciaram em setembro de 2016, sendo integradas por um cronograma de ações que considerou as demandas apresentadas pela pesquisa científica, mas também pela natureza do Programa de Iniciação Científica ofertado pelo IFPA, orientado para os discentes do Ensino Integrado, com bolsa de duração de um ano.

Nesse momento, a discente selecionada para integrar a pesquisa, cursava o primeiro ano do Ensino Médio exigindo, portanto, adaptações no curso das ações previstas. Constituindo uma série de desafios que contemplam as peculiaridades da inserção na pesquisa.

Dessa forma, no relato das atividades desempenhadas pela discente, o momento inercial foi integrado pelo levantamento de referencial teórico composto por artigos, Leis, livros, relatórios de pesquisa, entre outros. Somou-se ainda o respectivo fichamento com ênfase para as leituras geográficas do processo de produção do espaço e das questões ambientais, para elaboração textual que integrou a fundamentação teórica.

Posteriormente, as atividades foram compostas pela elaboração de material cartográfico, a partir do uso do software Google Earth, objetivando a caracterização do recorte espacial, mediante efetivação de leituras que possibilitassem a identificação dos possíveis impactos socioambientais negativos e positivos.

As práticas de campo foram efetivadas em conjunto com a orientadora, mediadas pela elaboração de planilha visando o levantamento e caracterização dos impactos ambientais. A planilha considerou os critérios organizados em: erosão e permeabilidade do solo; qualidade do ar; nível de ruído; cobertura vegetal, fauna, população, tráfego; aspectos sobre a saúde humana; disposição inadequada dos resíduos e insumos; invasão residencial e/industrial na margem do rio; geração de emprego. Para a abordagem dos aspectos supramencionados, fez-se uso do método check-list como subsídio para uma 


\section{ISSN - 2359-6007}

análise crítica da realidade.

No âmbito dos impactos, verificou-se o predomínio de práticas que concorrem para cenários negativos diante do uso inadequado dos recursos e a ausência de manutenção das propriedades dos elementos que compõem o recorte adotado para análise (Figura 2).
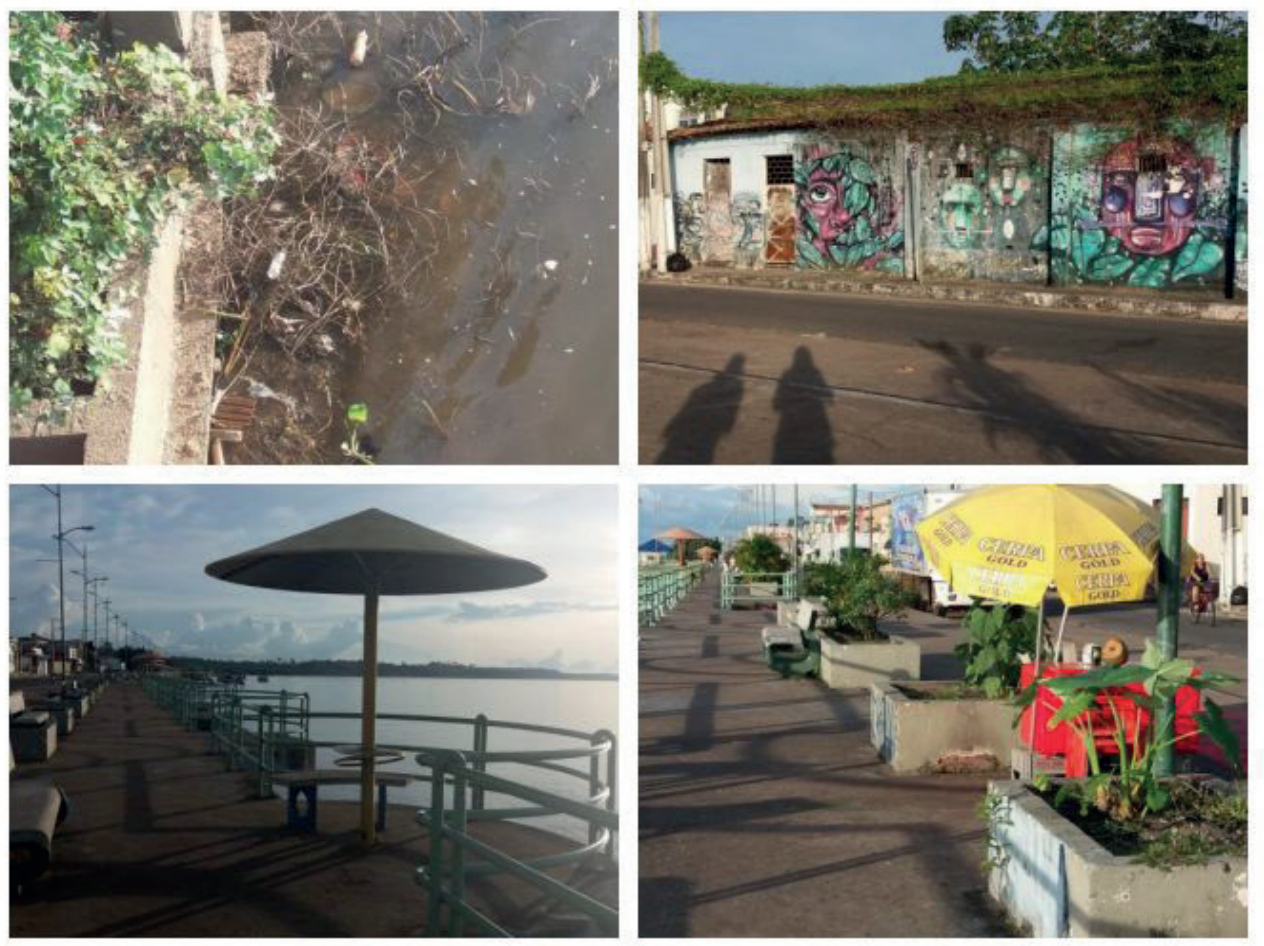

Figura 2: Mosaico com os principais impactos negativos encontrados na Orla. Fonte: Acervo particular dos autores (julho de 2017).

As práticas de campo foram compostas pela conferência dos elementos elencados no Chek-list mediante o uso da observação sistemática, além do registro fotográfico que possibilitou a constituição das análises efetivadas em reuniões semanais. Objetivando identificar o papel assumido pelas atividades realizadas no Projeto após a conclusão do plano de ações, foi realizada a aplicação de questionário com a bolsista.

Dessa forma, quando questionada sobre a importância da prática no Projeto de Iniciação Científica, ela observa que: "É importante para o aluno aprender mais, pois para desenvolver um projeto de pesquisa é necessário buscar o conhecimento existente na área, conhecer o problema e a forma de enfrentálo, coletar e analisar dados e por fim construir nossas conclusões". Retomando as observações de Cavalcanti (2008), ao discorrer sobre a relevância assumida pela participação ativa dos discentes no processo de construção do conhecimento.

Quando perguntada sobre a importância da bolsa para as atividades de ensino, foi destacado que a bolsa foi importante auxílio para as pesquisas e atividades de campo. Foi perguntado ainda se a Iniciação Científica contribuiu para o trabalho com as disciplinas da comum e da base técnica. Nesse momento, a discente observou que "Contribuiu bastante, pois na elaboração do projeto pudemos testar técnicas e teorias aprendidas em sala de aula e o fato de ler muito, melhorou o desempenho nas 
disciplinas".

Ao ser indagado se Iniciação Científica atrapalhou em algum momento as atividades em sala de aula, a discente ressaltou que "de forma alguma, pois a orientadora sempre escolheu horários apropriados e fez reuniões de forma que não sobrecarregasse as atividades em sala de aula".

Além disso, perguntou-se quais as principais dificuldades encontradas durante as atividades de Iniciação Científica, nesse momento, ela ressaltou que "no projeto não enfrentei dificuldades durante as atividades". Quando interrogada se ela acredita que as atividades de Iniciação Científica contribuíram para a compreensão das etapas que integram a Pesquisa Científica, a discente observou que "Sim, não só contribuiu como foi de extrema importância para a compreensão de todo o processo do trabalho científico, considerando que a participação foi ativa em todas as etapas", corroborando dessa forma, com as considerações de Furlan (2006), acerca da do papel assumido pelos projetos na construção de conhecimentos.

O conjunto de observações indica que a Iniciação subsidiou a construção de conhecimentos relacionados à prática científica, pois como observam Moura, Barbosam, Moreira (2008), essa ação é fundamental para reflexões acerca dos conhecimentos disponibilizado. Além disso, constata-se a contribuição para a construção de conhecimentos sobre conceitos básicos da Geografia, especialmente associados à dinâmica de produção do espaço urbano e impactos ambientais como defendido por Cavalcanti (2008). Auxiliando ainda nos processos elementares de leitura e interpretação textual, assim como a adoção do fichamento como prática para auxiliar as atividades das demais disciplinas. Destaca-se também que em contexto marcado pelos expressivos índices de retenção no ano letivo de 2016, a discente obteve êxito na aprovação em todas as disciplinas.

\section{CONCLUSÃO}

As análises revelaram que o ensino-aprendizagem envolve um conjunto diversificado de demandas que exigem a integração entre diferentes habilidades na prática docente, além de recursos capazes de auxiliar a ampliação de conhecimentos nos diferentes ramos do conhecimento. Quando analisados os conhecimentos geográficos, observa-se a relevância das atividades teóricas, mas também das ações práticas orientadas para a constituição de aprendizagem continuada.

Nesse universo, verifica-se que os projetos de Iniciação Científica constituem subsídios para a construção do conhecimento, na medida em que auxiliam no desenvolvimento de habilidades relacionadas à prática da pesquisa, possibilitando a sistematização das atividades, assim como a significativa melhoria em ações como leitura, interpretação e análises de conteúdo. Além da inserção em técnicas de pesquisa, coleta e análise de dados.

A abordagem dessas observações no curso Integrado em Controle Ambiental, mediado pelo questionamento à discente, no campus Marabá Industrial, revelou a importância da ampliação da prática de pesquisa entre os diferentes ramos dos conhecimentos, objetivando entre outros a integração entre saberes e o estímulo para as abordagens teóricas e práticas. 0 relato da experiência discente apontou também que a Iniciação Científica representou uma atividade capaz de desenvolver habilidades e 
auxiliar na construção de conhecimentos.

\section{REFERÊNCIAS}

1. CAVALCANTI, L S. A geografia escolar e a cidade: ensaios sobre o ensino da geografia para vida urbana cotidiana. Campinas, SP: Papirus, 2008.

2. CASTROGIOVANNI, Antonio Carlos; GOULART, Lígia Beatriz. A questão do livro didático em geografia elementos para uma análise. In: CASTROGIOVANNI, Antonio Carlos, et.al. (orgs.). Geografia em sala de aula: práticas e reflexões. 4. ed. Porto Alegre: Editora da UFRGS, 2003. p. 65-76.

3. FENKER, E. A. Análise custo-benefício aplicável ao meio-ambiente. Disponível em:http:// noticias.ambientebrasil.com.br/artigos/2007/01/22/28939-valor econômico da biodiversidade.html. Acesso em: 02 fev. 2016.

4. FURLAN, Sueli Angelo. Projetos de estudo em Biogeografia: uma abordagem significativa da construção de projetos. In: CASTELLAR, Sonia (Org.). Educação Geográfica: teorias e práticas docentes. 2. ed. São Paulo: Contexto

5. INSTITUTO BRASILEIRO DE GEOGRAFIA E ESTATÍSTICA. Censo demográfico- População. 2010. Disponível em:< http://censo2010.ibge.gov.br/>. Acesso em: 12 mar. 2016.

6. LESSARD C. e TARDIF M. O trabalho docente: elementos para uma teoria da docência como profissão de interações humanas. 7. ed. Rio de Janeiro: Vozes, 2012.

7. INSTITUTO FEDERAL DO PARÁ-Campus Marabá Industrial. Projeto Pedagógico de Curso (PPC) - Controle Ambiental, Marabá, 2016.

8. ___ Plano de Desenvolvimento do Campus (PDC), Marabá, 2017.

9. KAERCHER, Nestor. André. Desafios e Utopias no Ensino da Geografia. 3. ed. - Santa Cruz do Sul/RS:EDUNISC, 2003

10. LESSARD C. \& TARDIF M. O trabalho docente: elementos para uma teoria da docência como profissão de interações humanas. 7. ed. Rio de Janeiro: Vozes, 2012.

11. MENDONÇA, F. de A. S.A.U. - Sistema Ambiental Urbano: uma abordagem dos problemas socioambientais da cidade. In: MENDONÇA, Francisco. Impactos socioambientais urbanos. Curitiba: UFPR, 2004. p.185-207.

12. MOURA, Dácio G., BARBOSA Eduardo F., MOREIRA Adelson F. O aluno pesquisador. Anais... XV ENDIPE - Belo Horizonte/2010. Disponível em:< https://tecnologiadeprojetos.files.wordpress. com/2016/10/7bfd0f0b4f-7178-443e-bea1-47c03c68ba627d_20aluno20pesquisador2020texto20para 20xv20endipe2020102020dc3a1cio20et20al20pdf.pdf> Acesso em: 29 jan. 2017. 
13. PERRENOUD, P. Dez novas competências para ensinar. Artmed, 2000.

14. SALIS, Cleide Lopes; OLIVEIRA, Tatiana Souto Maior de. A problemática das enchentes e cheias periódicas no município de Marabá/PA: o caso do bairro Santa Rosa. Meio ambiente e sustentabilidade, 2013. Disponível em: http://www.grupouninter.com.br/revistameioambiente/index. php/cadernomeioambiente/article/view/200> Acesso em: 02 mar. 2016.

15. SILVA, S. S. ; MELO, M. S. R. ; SILVA, J. A. A maquete como instrumento de representação do espaço geográfico. Revista FSA (Faculdade Santo Agostinho), v. 8, p. 235-248, 2011.

16. TARDIF M. Saberes docentes e formação profissional. 13. ed.Rio de Janeiro: Vozes, 2012. 